\title{
Modelling the accessibility to public local transport to increase the efficiency and effectiveness of the service: the case study of the Roccella area in Palermo
}

\author{
M. Migliore, A. Lo Burgio, L. Maritano, M. Catalano \\ \& A. Zangara \\ Department of Energy, Transport Research Group, \\ University of Palermo, Italy
}

\begin{abstract}
This paper suggests a methodology to assess, through quantitative indicators, the public transport based accessibility inside an urban area. Such indicators derive from two functions, one called the "activity function", allowing for the presence of generators and attractors of mobility and another termed the "impedance function", measuring the generalized cost of public transport journeys. The proposed method was tested and applied to a zone on the outskirts of Palermo (capital of the Sicilian Region), to evaluate the effects of a new tram line, which is under construction and will be activated by the end of 2012. The study shows that such a line is not sufficient to enhance significantly the accessibility of this zone except near the tramway. Therefore, to reach a high level of accessibility in the whole study area minimising, at the same time, the public transport operating costs, it could be better to plan an integrated system in which the tram service is supported by new bus lines or novel routes of the existing ones. Today, many European cities face the shortage of public funds, which raises the issue of efficiency for local policy actions. Given the above, we intend to provide the local town authorities with methodological tools to improve public transport performance and consequently accessibility, under severe budget constraints, by the re-organization of the service and a better exploitation of existing facilities.
\end{abstract}




\section{Introduction}

Accessibility and mobility are related phenomena: accessibility is a property of places, which may foster or, on the contrary, hinder the mobility of people, information and goods. As such, accessibility can be seen as a key decision variable for urban policies with the aim of creating new residential location and economic development opportunities.

Moreover, accessibility, as a measure of the ease of reaching urban services, could play an important role in evaluating social inclusion; in this perspective, it could be a useful criterion to drive social equity-orientated local policies.

The location pattern of residences and enterprises in a given context is one of the main factors generating the mobility demand. On one hand, transport demand derives from the households' need to use urban functions scattered over the town. On the other hand, transport supply characteristics (travel times, costs, level of congestion, etc.) determines the accessibility degree of the different zones, which, in turn, affects mobility demand.

In this research, we consider the "active" accessibility and the "passive" one (Cascetta et al. [1]). The former, in relation to a certain origin, is a proxy of the opportunity of getting to the various destinations of the study area for a given purpose (e.g. working, shopping, etc.). The latter, instead, is a proxy of the opportunity for a destination place of being reached by users moving from all the different zones of the study area.

Given the above, in this paper, we propose a methodology to assess the public transport based accessibility levels within an urban context, which could be, for the local authorities, an effective tool to improve public transport performance, under severe budget constraints, by the mere re-organization of the service. The development of public transport through low cost strategies is a top issue nowadays, considering that the shortage of public funds for urban policies is widespread throughout Europe.

Such a methodology was tested and applied to a zone on the outskirts of Palermo (capital of the Sicilian Region, in the South of Italy), to forecast the effects of a new tram line, which is under construction and will be activated by the end of 2012.

Before going into details, let us give, in the next section, some data about the population and the transportation system of Palermo.

\section{Mobility in Palermo}

According to the last population census (2001), the municipal area of Palermo is 160.11 square kilometers and the residents are 729,855; consequently, the density is around 4,558 inhabitants per square kilometer. The urban area has developed longitudinally around the old city over the years, since its expansion towards hinterland is limited by the presence of a mountain chain (Fig. 1).

Palermo is characterized by a remarkable imbalance of the modal split in favor of private transport (Table 1) and by accessibility heterogeneity across zones. 


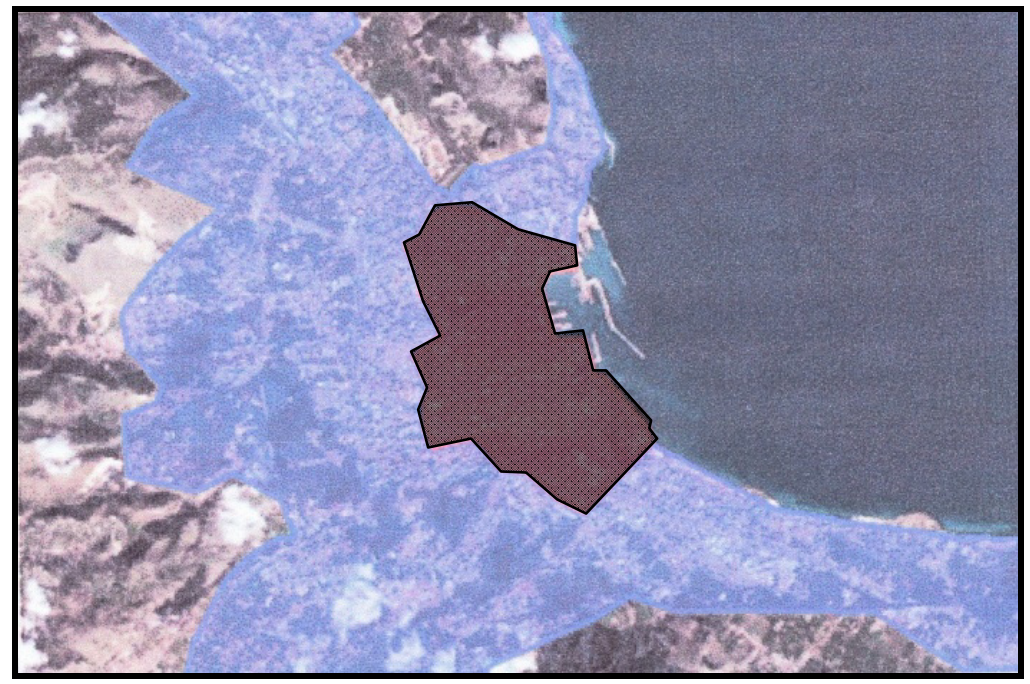

Figure 1: $\quad$ Old city (in dark) and conurbation of Palermo.

The local public transport interferes with the private one except for some rail links and some other road connections with bus lanes, whose length represents nearly $10 \%$ of the whole bus network.

Although many origin-destination pairs are served for the widespread possibility of bus-bus interchange, road public transport is not competitive, owing to its bad performance in terms of commercial speed and frequency (Table 2).

Moreover, a railway line connects Palermo with the near regional airport: trains stop at some important nodes inside the town and the service frequency is two trains per hour.

\section{The tramway network of Palermo}

Three tram lines (Fig. 2), according to the agenda of the local authorities, should be introduced by the end of 2012. The idea is to integrate the current public transport network with the tram service that, in virtue of its capacity and high frequency, is particularly suitable for most mobility demand in Palermo, characterized by frequent and short-stay trips.

So, the above tram lines should interact with the bus and rail networks, so as to increase the number of o-d links and to reduce the amount of bus lines serving some zones of the town (many bus lines does not necessarily mean high levels of service frequency).

The tram line (line 1 - Roccella) crossing the Roccella zone (see Fig. 2), which is our study area, will be developed along a route of about $6 \mathrm{~km}$ on which 15 stops will be placed. This line will provide a frequency of 12 vehicles/hour, a maximum speed of $70 \mathrm{Km} / \mathrm{h}$ and a commercial speed of $20 \mathrm{Km} / \mathrm{h}$. Furthermore, 
Table 1: Passenger mobility in Palermo (source: Urban Transport Plan, 2009).

\begin{tabular}{|c|c|}
\hline Daily trips by car within the municipal area & 700,000 \\
\hline Daily crossing and interchange trips by car & 200,000 \\
\hline Car occupancy rate (individuals/car) & 1.3 \\
\hline $\begin{array}{c}\text { Rush hour flow of passengers using private car } \\
\text { (within the municipal area) }\end{array}$ & 74,000 \\
\hline $\begin{array}{c}\text { Rush hour flow of passengers using private car } \\
\text { (crossing and interchange trips) }\end{array}$ & 16,000 \\
\hline $\begin{array}{c}\text { Rush hour flow of passengers using bus } \\
\text { (within the municipal area) }\end{array}$ & 20,000 \\
\hline
\end{tabular}

Table 2: $\quad$ Bus service characteristics at the interchange nodes.

\begin{tabular}{|c|c|c|c|c|}
\hline Nodes & $\begin{array}{c}\text { Average } \\
\text { commercial } \\
\text { speed } \\
\text { [Km/hour] }\end{array}$ & $\begin{array}{c}\text { Average } \\
\text { frequency } \\
\text { [buses/hour] }\end{array}$ & $\begin{array}{c}\text { Minimum } \\
\text { frequency } \\
\text { [buses/hour] }\end{array}$ & $\begin{array}{c}\text { Maximum } \\
\text { frequency } \\
\text { [buses/hour] }\end{array}$ \\
\hline 1 & 16.00 & 3 & 1 & 4 \\
\hline 2 & 15.30 & 3 & 2 & 6 \\
\hline 3 & 15.10 & 3 & 2 & 5 \\
\hline 4 & 17.10 & 3 & 2 & 5 \\
\hline 5 & 19.70 & 2 & 1 & 6 \\
\hline 6 & 16.60 & 2 & 1 & 6 \\
\hline Mean & 16.63 & 2 & 1 & 15 \\
\hline
\end{tabular}

nine low floor tramcars, with a carrying capacity of 250 passengers, will be employed, which will result in a total service capacity of 3,000 passengers/hour. In the next section, we outline the method followed in this research for measuring public transport based accessibility.

\section{Measuring accessibility}

One of the most used approaches to quantify accessibility is the physicaldeterministic technique (Cascetta et al. [1]), which derives the relevant indicators from the combination of two functions, one called "activity function" allowing for the presence of generators and attractors of mobility, and another termed the “impedance function” expressing the disutility of transport (Wegener et al. [2]). 


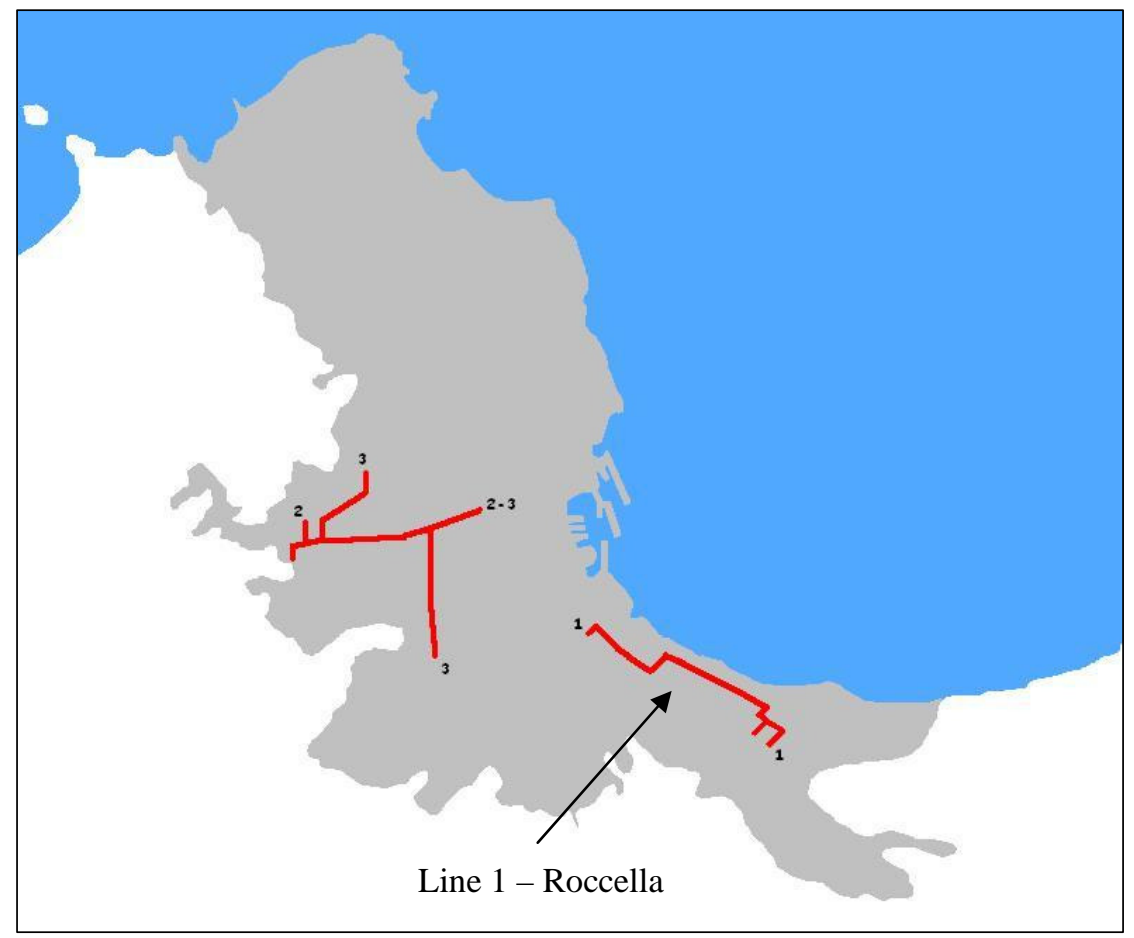

Figure 2: $\quad$ The future tramway network of Palermo.

In this work, active and passive accessibility indices are defined, in accordance with the above approach, in the following way:

$$
A c c_{\text {pass }(d)}=\sum_{o} \operatorname{Res}(o)^{\beta_{1}} \times \exp \left(\beta_{2} \times C_{g e n(o, d)}\right)
$$

where:

$\operatorname{Res}(o)$ is the number of individuals residing in zone $o$; $C_{g e n(o, d)}$ is the generalized travel cost $(€)$ to go from zone $o$ (centroid) to bus stop $d$

$\beta_{1}$ e $\beta_{2}$ are parameters whose estimated values are drawn from the scientific literature (Cascetta et al. [1]); they are equal to 0.65 and 1.25 , respectively.

$$
A c c_{a t t(o)}=\sum_{d} \operatorname{Emp}(s, d)^{\beta_{3}} \times \exp \left(\beta_{4} \times C_{g e n(o, d)}\right)
$$

where:

$\operatorname{Emp}(s, d)$ is the number of employees of zone $d$ working in sector $s$; $C_{g e n(o, d)}$ is the generalized travel cost $(€)$ to go from bus stop $o$ to zone $d$ (centroid);

$\beta_{3}$ e $\beta_{4}$ are parameters whose estimated values are drawn from the scientific literature (Cascetta et al. [1]); they are equal to 0.85 and 1.25 , respectively. 
The generalized travel cost was determined by assigning a monetary value ( $5 € /$ hour) to the service access time, that is the sum of the time spent waiting at the bus stop (headway/2) and the walking time for the centroid-bus stop link (pedestrian arc length divided by a speed of 0.85 meters/second). Such a value of time was derived from a recent study by Catalano et al. [9].

Moreover, it was assumed a range of influence of 250 meters for bus stops and of 300 meters for tram stops.

\section{The case study of the Roccella area}

The indices previously illustrated were applied to the Roccella area, in the suburbs of Palermo, that will be crossed by the new tram line 1 (see section 3 ). This study area was divided into traffic zones inside which most mobility generation and attraction points are represented by a single centroid.

In more detail, four scenarios were analysed: the first, Scenario 0, representing the state of the art, assumes that the present bus service is the only mode of transport in competition with private car; the second, Scenario 1, assumes that the study area is served only by the new tram line 1 , no bus service is available; under the third, Scenario 2, the new bus service (see Table 3 for their characteristics), which has been planned by the local bus company (five lines less with respect to the current situation), overlaps with the future tram line 1 - Roccella; in the end, under Scenario 3, we propose to integrate the tram service with four feeder bus lines (see Table 4 for their characteristics).

It was performed both a transport analysis, through a step-by-step evaluation of the accessibility indices under the different scenarios, and an economic analysis, to calculate the yearly cost to run the public transport services. We chose to take into account only running costs and to overlook the construction costs for the new tram line, since these do not differ across the scenarios. The

Table 3: $\quad$ The new bus service proposed by local bus company.

\begin{tabular}{|c|c|c|c|c|}
\hline Line & $\begin{array}{c}\text { Frequency } \\
\text { [buses/hour }]\end{array}$ & Length [Km] & $\begin{array}{c}\text { Commercial speed } \\
{[\mathrm{Km} / \mathrm{h}]}\end{array}$ & $\mathrm{N}^{\circ}$ Buses \\
\hline 224 & 3.75 & 10.20 & 15.30 & 5 \\
\hline 211 & 4.62 & 5.30 & 12.23 & 4 \\
\hline 227 & 4.29 & 5.70 & 12.21 & 4 \\
\hline 226 & 4.29 & 7.80 & 15.60 & 4 \\
\hline 231 & 4.00 & 7.10 & 14.20 & 4 \\
\hline 212 & 4.00 & 7.40 & 11.68 & 5 \\
\hline & & & Total buses & 26 \\
\hline
\end{tabular}


Table 4: $\quad$ The four feeder bus lines proposed under Scenario 3.

\begin{tabular}{|c|c|c|c|c|}
\hline Line & $\begin{array}{c}\text { Frequency } \\
\text { [buses/hour] }\end{array}$ & $\begin{array}{c}\text { Length } \\
{[\mathrm{Km}]}\end{array}$ & $\begin{array}{c}\text { Commercial } \\
\text { speed }[\mathrm{Km} / \mathrm{h}]\end{array}$ & $\begin{array}{c}\mathrm{N}^{\circ} \\
\text { Buses }\end{array}$ \\
\hline 1 & 6 & 4.70 & 15 & 3 \\
\hline 2 & 6 & 3.93 & 15 & 3 \\
\hline 3 & 6 & 6.90 & 15 & 4 \\
\hline 4 & 6 & 4.21 & 15 & 3 \\
\hline \multicolumn{4}{|r}{} \\
\hline
\end{tabular}

computations were based on hourly cost parameters, in the case of 18 operating hours a day. For bus, an average cost of $4 € /$ vehicle-km was adopted, while, for tram, the lower value of $3 € /$ vehicle-km was employed (source: survey by the authors).

Based on a Geographic Information System, we created thematic maps to highlight the improvement/worsening in the active/passive accessibility produced by a certain scenario with respect to another.

From the comparison between Scenario 1 (only the tram service) versus Scenario 0 (the present situation), emerges an improvement of the passive accessibility for few zones of the study area and a general worsening of the active one.

Whereas, the comparison between Scenario 2 against the current situation reveals a remarkable enhancement of both accessibility indicators for almost all zones of the study area (Figs 3 and 4). Notwithstanding, Scenario 2 presents a

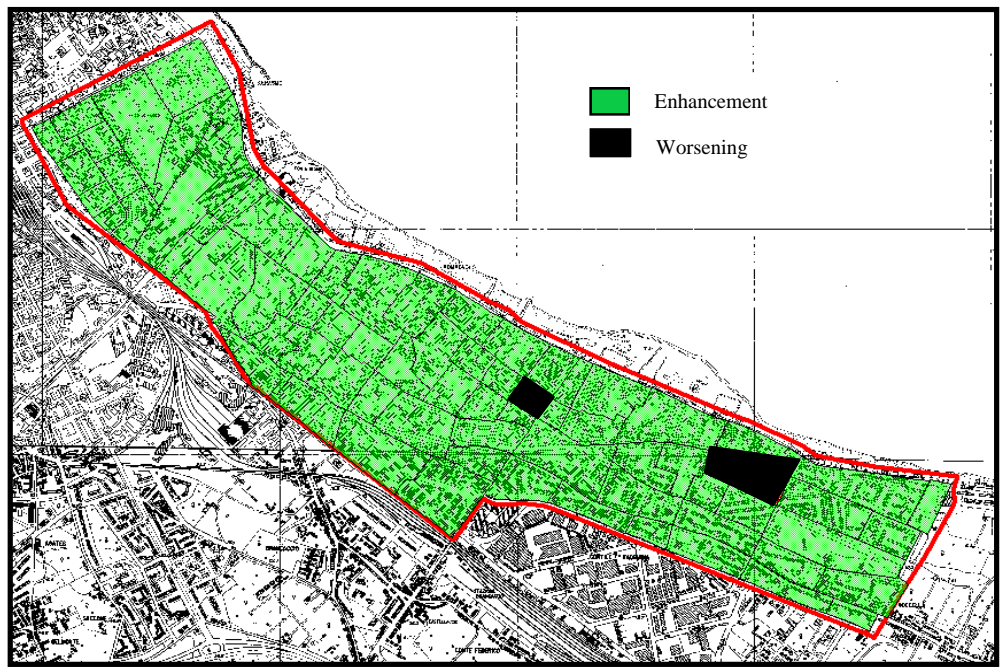

Figure 3: Comparison between Scenario 2 and Scenario 0 (active accessibility). 


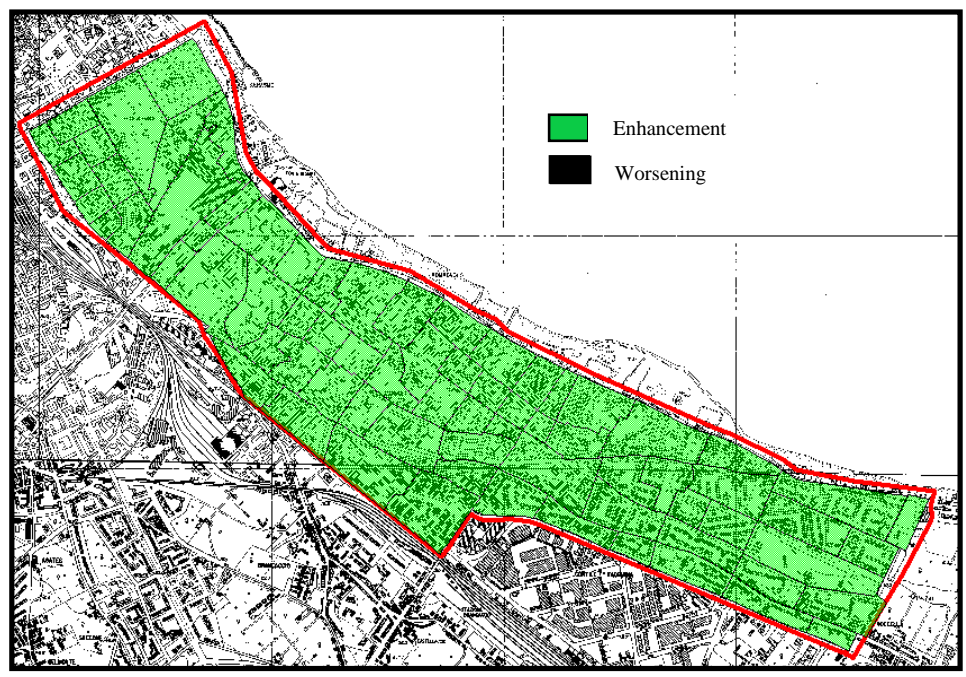

Figure 4: Comparison between Scenario 2 and Scenario 0 (passive accessibility).

problem: the tram service and the bus one, although managed by the same company, are in competition; in fact, under Scenario 2, many bus lines overlap or run in a parallel direction with the tramway, within its sphere of influence (Fig. 5), and a bus-tram coordination, to maximise public transport frequency, would be very difficult to implement.

Under Scenario 3, we propose four bus lines feeding the tramway, so as to avoid an inner competition limiting revenues for the tram service, which has required high investment costs. Also Scenario 3, in relation to the no change-

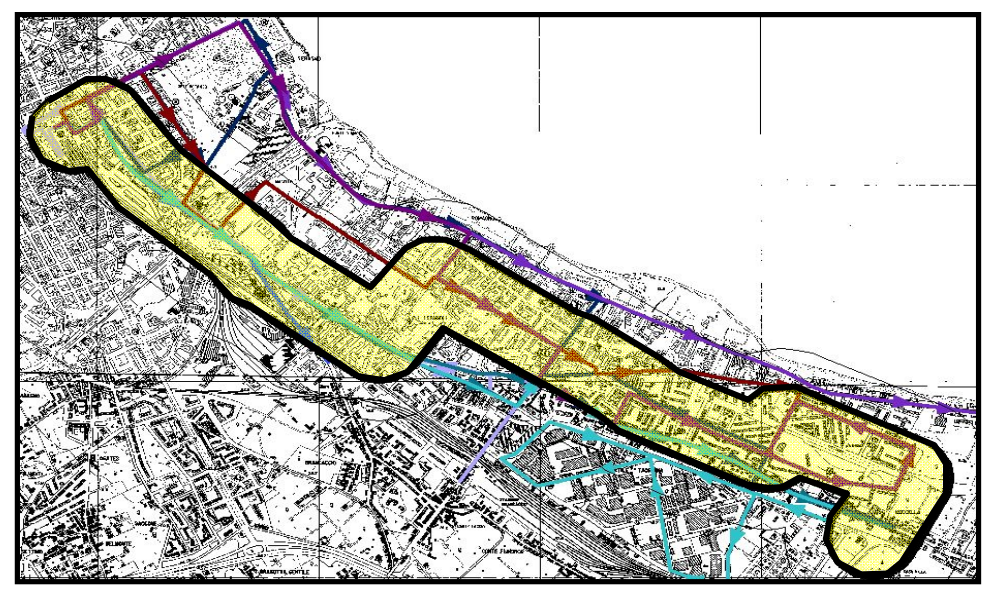

Figure 5: Tramway buffer and bus network planned by the public transport company. 


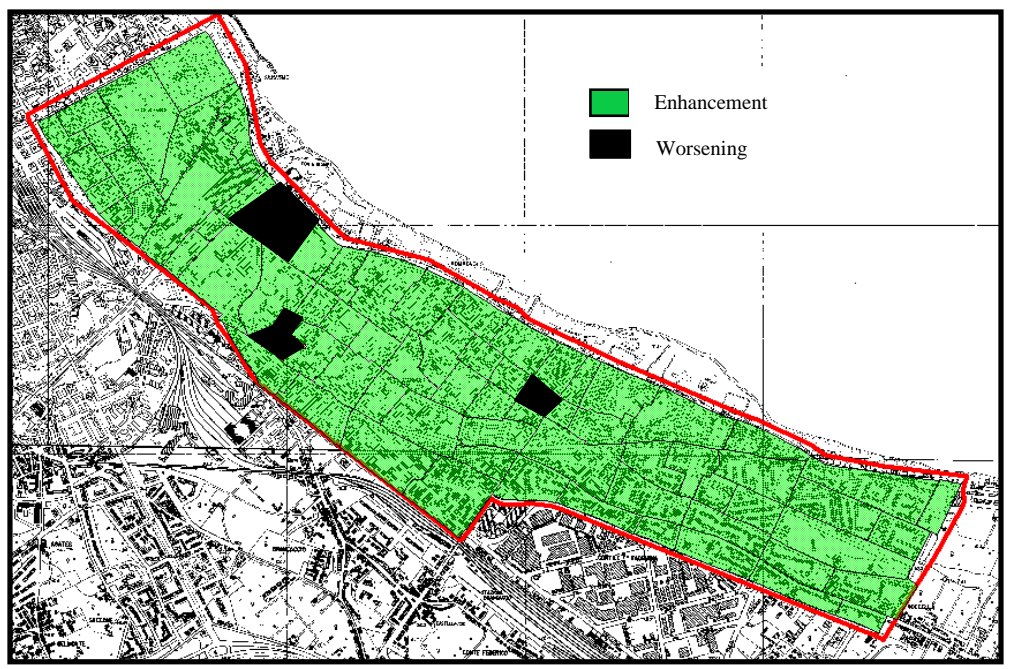

Figure 6: Comparison between Scenario 3 and Scenario 0 (active accessibility).

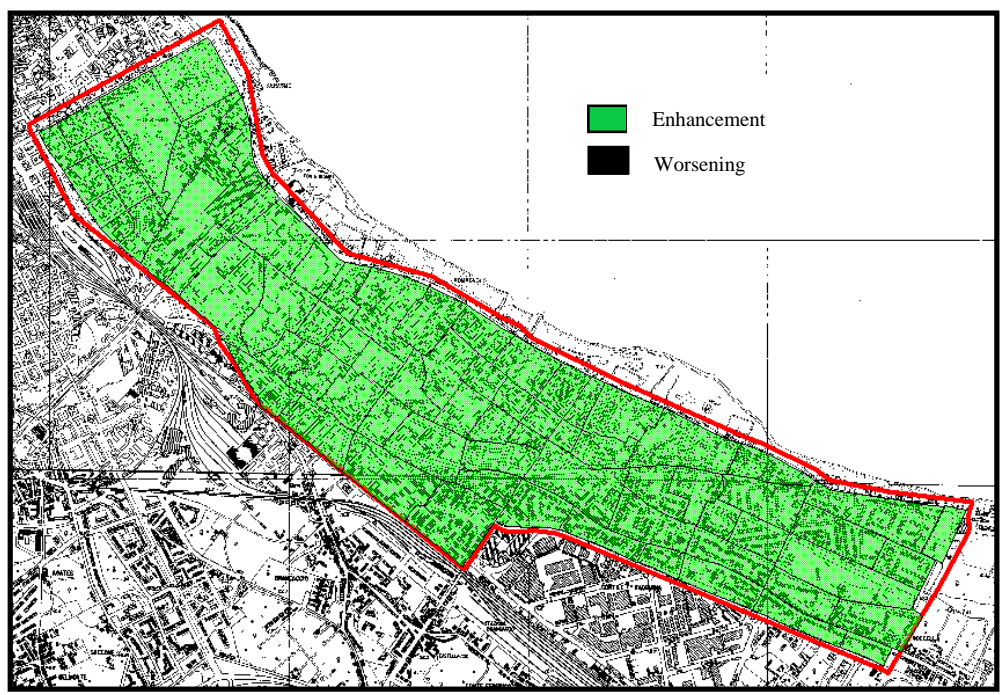

Figure 7: Comparison between Scenario 3 and Scenario 0 (passive accessibility).

option, implies a global improvement in accessibility (Figs 6 and 7): the passive accessibility rises everywhere, while the active one reduces only in three zones.

Despite its benefits, as to the active and passive accessibility levels, Scenarios 3 is outperformed by Scenario 2. Anyway, let us remind that the solution proposed by the authors prevents the nonsense of a bus-tram competition; in 
addition, the economic analysis points out that it is far better in terms of yearly operating costs than Scenario 2, which represents the point of view of the local bus company. Evidence of this is provided in Tables 5-6 showing that, with respect to the no change-option, Scenario 3 leads to a $8 \%$ cost saving, whilst Scenario 2 would cause running costs to rise by $38 \%$.

Table 5: Quantitative indicators under the four scenarios.

\begin{tabular}{|c|c|c|c|}
\hline Scenario & $\begin{array}{c}\text { Total running cost } \\
(€ / \text { year })\end{array}$ & $\begin{array}{c}\text { Active } \\
\text { accessibility } \\
\text { index }\end{array}$ & $\begin{array}{c}\text { Passive } \\
\text { accessibility } \\
\text { index }\end{array}$ \\
\hline 0 & $3,393,023.15$ & 8,442 & 9,572 \\
\hline 1 & $2,696,328.00$ & 4,496 & 18,205 \\
\hline 2 & $4,692,784.95$ & 20,075 & 75,792 \\
\hline 3 & $3,111,868.41$ & 15,431 & 60,442 \\
\hline
\end{tabular}

Table 6: $\quad$ Cost variation with respect to Scenario 0.

\begin{tabular}{|c|c|}
\hline Scenario & $\begin{array}{c}\text { Variation in total running cost } \\
\text { with respect to Scenario 0 }\end{array}$ \\
\hline 1 & $-21 \%$ \\
\hline 2 & $38 \%$ \\
\hline 3 & $-8 \%$ \\
\hline
\end{tabular}

\section{Conclusions}

The solution proposed in this work to strengthen public transport in a suburban area of Palermo is a compromise between the aim of enhancing accessibility and the need to optimise the use of the scarce resources of the local administration. Hence, the described approach focusing on the key-variable of accessibility could be, for local policy makers with severe budget constraints, a useful methodological tool to improve public transport standards by a more efficient exploitation of existing facilities.

\section{References}

[1] Cascetta E, Nuzzolo A. Coppola P., A system of mathematical models for the simulation of land-use and transport interactions. In L. Sucharov and C. Brebbia Eds. Proc. of the $5^{\text {th }}$ Int. Conf. Urban Transport and the Environment V, WIT Press, 2000.

[2] Wegener M. et al., Study Program on European Spatial Planning, W.G. 1.1 - Geographical Position, Final Report, 2000. 
[3] Amoroso S., Salvo G., Zito P., L’accessibilità dei trasporti pubblici come strumento per vincere l'esclusione sociale, 2000.

[4] Litman T., Evaluating Transportation Land-use Impacts, Victoria Transport Policy Institute, 2009.

[5] Wilson A.G., Land use/transport interaction models - past and future, Journal of Transport Economics and Policy, 32, 3-23, 1997.

[6] E. Cascetta, Teoria e metodi dell'ingegneria dei sistemi di trasporti, UTET, 1998.

[7] Wegener, M., and Furst, F., Land-use and transport interaction: state-of-theart, Project funded by the European commission under the transport RTD programme of the $4^{\text {th }}$ framework programme, 1999.

[8] Hansen, W.G., How accessibility shapes land use, Journal of the American Institute of Planners, 25, 73-76, 1959.

[9] Catalano, M., Migliore, M. \& Lo Casto, B., Car sharing demand estimation and urban transport demand modelling using stated preference techniques. European Transport, 40, pp. 33-50, 2008. 